\title{
Risk assessment tool for incontinence-associated dermatitis in elderly patients combining tissue tolerance and perineal environment predictors: a prospective clinical study
}

\author{
This article was published in the following Dove Press journal: \\ Chronic Wound Care Management and Research \\ 21 October 2014 \\ Number of times this article has been viewed
}

\author{
Yoshie Ichikawa-Shigeta' \\ Hiromi Sanada ${ }^{2}$ \\ Chizuko Konya ${ }^{3}$ \\ Saldy Yusuf' \\ Supriadi' \\ Junko Sugama'
}

'Department of Clinical Nursing, Institute of Medical, Pharmaceutical and Health Sciences, Kanazawa University, Ishikawa, Japan; ${ }^{2}$ Department of Gerontological Nursing/Wound Care Management, Graduate School of Medicine, University of Tokyo, Tokyo, Japan; ${ }^{3}$ Department of Adult Nursing, Kanazawa Medical University, Ishikawa, Japan
Background: Elderly patients with incontinence are at risk of developing incontinenceassociated dermatitis (IAD). Although perineal risk factors of IAD have been identified, the contribution of tissue tolerance to IAD remains poorly understood.

Objective: This study aimed to identify predictors of IAD development in three categories of potential risk factors: perineal environment, tissue tolerance, and toileting ability.

Methods: This was a prospective clinical study, conducted at a long-term medical facility in Japan between November 2011 and April 2012. The subjects were elderly female patients with urine and/or fecal incontinence, and constantly wearing absorbent products. The patients were monitored during 42 days for the onset of IAD and the emergence of potential risk factors of IAD related to tissue tolerance (skin hydration status, maceration, erythema index [EI], etc), perineal environment (urination, stool properties, etc), and toileting ability (mobility and cognitive awareness). The risk factors were identified by univariate and multiple logistic regression analysis. Receiver operating characteristic (ROC) curve analysis was conducted to evaluate the predictive validity of the risk factors.

Results: Among the 46 patients enrolled, IAD developed in 25 (54.3\%). The factors significantly associated with IAD development were loose or liquid stools (odds ratio [OR]: 20.612, 95\% confidence interval $[\mathrm{CI}]: 1.118-379.852, P=0.042)$, malodorous urine (OR: $37.094,95 \%$ CI: 3.480-395.399, $P=0.003$ ), and EI $\geq 46$ (OR: 35.191, 95\% CI: 5.254-235.729, $P<0.001$ ). The ROC curve analysis identified EI $\geq 46$ as the most reliable predictor of IAD (sensitivity: 0.92, specificity: 0.81). These factors were integrated into a new risk assessment tool for the development of IAD in elderly patients with incontinence.

Conclusion: This study demonstrates that EI constitutes a more valid predictor than perineal factors to monitor patients in clinical settings and to prevent the development of IAD.

Keywords: nursing, risk factor, erythema index, liquid stool, malodorous urine

\section{Introduction}

Incontinence-associated dermatitis (IAD) is an inflammation of the skin that occurs when urine or stool comes into contact with perineal or perigenital skin. ${ }^{1}$ The prevalence of IAD among elderly people with incontinence ranges from $5.7 \%$ to $25 \%$, ${ }^{2-4}$ whereas its incidence among elderly people ranges from $3.4 \%$ to $7.6 \%{ }^{5,6}$ IAD considerably affects an individual's physical and psychological well-being. Therefore, there is an urgent need for practical risk assessment tools to prevent IAD development.

The efficiency of risk assessment tools depends on the validity and reliability of the risk factors of IAD. Previous studies investigated the perineal environment ${ }^{3,5}$ and tissue
Correspondence: Junko Sugama Department of Clinical Nursing, Institute of Medical, Pharmaceutical and Health Sciences, Kanazawa University, 5-I I-80 Kodatsuno, Kanazawa, Ishikawa 920-0942, Japan

Tel +81762652555

Fax +8I 762652555

Email junkosgm@mhs.mp.kanazawa-u.ac.jp submit your manuscript $\mid$ www.dovepress.com Dovepress

Chronic Wound Care Management and Research 20I4:I 4I-47 
tolerance, especially skin moisture, ${ }^{7,8}$ to identify risk factors of IAD in elderly patients with incontinence. However, two studies on incontinence evaluated the characteristics of skin hydration based on moisture exposure. ${ }^{7,8}$ A Perineal Assessment Tool (PAT) was designed to measure the risk of perineal skin injury in hospitalized patients. ${ }^{9}$ Although the reliability of the PAT was reported to be acceptable, the PAT evaluates the severity of IAD and cannot evaluate the risk for IAD. In other words, none of these studies tested whether factors related to tissue tolerance, such as skin hydration, may constitute risk factors for the development of IAD.

We hypothesized that skin maceration caused by incontinence would be a risk factor for IAD. Brown ${ }^{10}$ defined a skin condition at risk for IAD, based on skin hydration/dehydration and altered $\mathrm{pH}$; however, instruments are required for these measurements, and this limits adequate monitoring. We previously described the impact of incontinence on skin characteristics. ${ }^{11}$ The results showed that dermal/epidermal hydration and skin redness (erythema index [EI]) were more severe in skin macerated by incontinence than in nonmacerated skin. These findings supported the development of inflammation in macerated skin. Furthermore, transepidermal water loss and skin $\mathrm{pH}$ were higher in macerated skin, suggesting that skin maceration reduces barrier functions. In addition, this study revealed that EI was the best identifier of skin maceration.

The purpose of the present study was to identify the risk factors for IAD development, including skin maceration and EI, in three major categories (perineal environment, tissue tolerance, and toileting ability), to evaluate their predictive ability for IAD development, and to develop a new risk assessment tool for IAD development.

\section{Materials and methods Study design and subjects}

A prospective clinical study was conducted in Japan between November 2011 and April 2012 at a long-term medical facility containing 500 beds for mostly elderly patients. This survey was allowed in two of the ten units. The inclusion criteria were female patients who had urine and/or fecal incontinence and who constantly wore absorbent products. The exclusion criteria were patients with skin damage on their buttocks or a serious medical condition. The women recruited were at high risk of developing skin maceration on their buttocks because a large skin area came in contact with urine regularly. The Medical Ethics Committee of Kanazawa University approved the study protocol (approval number 336). Written informed consent was obtained from all subjects or their family.

\section{Definition and diagnosis of IAD}

The visible skin characteristics of IAD were redness, skin loss, and rash. ${ }^{12}$ Also, a color chart was used to diagnose the shade of redness. Prior to the study, all nurses and health care assistants were trained using text containing pictures of IAD, during interactive sessions. When nurses or health care assistants detected skin lesions or skin changes indicative of IAD on the buttocks, they immediately contacted the researcher, who examined the skin and took pictures. The diagnosis of IAD was established independently by a fully trained researcher (Department of Wound Care Management), a dermatologist, and a wound/ostomy/continence nurse, using photographs. A consensus reached by two raters on the diagnosis of IAD was deemed acceptable. Interrater reliability (Fleiss's $\kappa$ ) was $\kappa=0.60$, which indicates fair to good reliability. ${ }^{13}$ The shade of redness was determined by a specific researcher.

\section{Identification of the potential risk factors for the development of IAD}

The variables considered are based on Brown's conceptual model of perineal dermatitis (Figure 1). ${ }^{10}$ Tissue tolerance was evaluated in terms of age, health status, body mass index (BMI), skin maceration, and EI. Subjects with a BMI $<18.5 \mathrm{~kg} / \mathrm{m}^{2}$ were classified as underweight. Skin maceration was defined according to our previous study showing that whitened skin, including whitening limited to a hair follicle, was in a swollen state. ${ }^{11}$ A fully trained researcher (Department of Wound Care Management), a dermatologist, and a wound/ostomy/ continence nurse independently diagnosed skin maceration on photographs. A consensus reached by two raters was deemed as acceptable for the diagnosis. Interrater reliability (Fleiss's $\kappa$ )

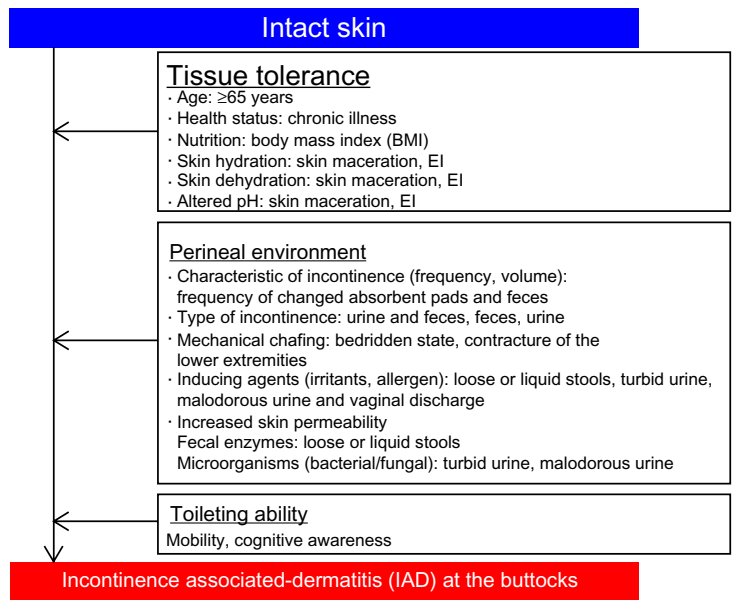

Figure I Categories of potential risk factors for the development of incontinenceassociated dermatitis in elderly patients.

Note: Data from Brown. ${ }^{10}$

Abbreviation: El, erythema index. 
was $\kappa=0.64$. EI was used for the quantification of erythema. ${ }^{14}$ Color calibration of all photographs was performed using adjustment levels on image editing software (Photoshop CS5; Adobe Systems, San Jose, CA, USA). Image calculations using EI were performed with ImageJ software (National Institutes of Health, Bethesda, MD, USA).

The perineal environment was evaluated in terms of the frequency of feces and change of the absorbent pads, as well as the type of incontinence; the bedridden state; contractures of the lower extremities; and the presence of loose or liquid stools, malodorous urine, turbid urine, and vaginal discharge. We checked whether pads were changed four or more times a day, because they are usually changed three times a day in clinical practice, based on the patient's urine volume. We checked whether patient's feces frequency was at least three times a week because a lower feces frequency indicates constipation. With respect to the fecal properties, loose or liquid stools were defined as type six or seven, according to the Bristol stool form scale. ${ }^{15}$ The urine was identified as turbid when urine sediment was confirmed on a patient's absorbent pad, and as malodorous when a specific researcher noticed that patient's urine smelled stronger than usual.

Toileting ability was assessed in terms of mobility and cognitive awareness. We determined whether patient could go to a toilet or use a bedside commode. Cognitive awareness was defined as whether the patient expressed the need to defecate and urinate.

\section{Procedure}

Data were collected during 42 consecutive days. Age, health status, BMI, type of incontinence, bedridden state, contractures of the lower extremities, mobility, and cognitive awareness were identified on day 1 of the investigation. To diagnose skin maceration and IAD and to calculate EI, photographs of the buttocks were taken weekly by the researcher at the time of pad changing. It took approximately 3 minutes per patient to take the photograph. The presence of turbid urine, malodorous urine, and/or vaginal discharge was assessed weekly by the researcher. Data on the frequency of absorbent pad changes, feces, and loose or liquid stools were collected from the medical records.

\section{Data analysis}

The following analysis was performed to identify the risk factors for the development of IAD (objective 1). First, the variables of tissue tolerance, perineal environment, and toileting ability showing $P<0.1$ by univariate analysis of relative risk (RR) were considered as potential risk factors. For the univariate analysis, the EI data were categorized by receiver operating characteristic (ROC) curve analysis. Second, multiple logistic regression analysis was performed to evaluate the risk factors. The potential risk factors identified in the different categories (tissue tolerance, perineal environment, and toileting ability) were analyzed separately because variables of the perineal environment are direct causes of IAD, whereas variables of tissue tolerance and toileting ability correspond to trigger factors for IAD.

The following analysis was performed to evaluate the predictive ability of the risk factors for the development of IAD using ROC curve analysis (objective 2). The parameters were the area under the curve (AUC), sensitivity, specificity, positive predictive value, negative predictive value, and positive likelihood ratio.

For the group of subjects who developed IAD, the data of the week before IAD diagnosis was analyzed. In contrast, for the group of subjects who did not develop IAD during the 42-day period, the data of the last week of the investigation were analyzed. All data were analyzed using SPSS for Windows, Version 20.0 (IBM Corp, Armonk, NY, USA), and statistical significance was set at $P<0.05$.

\section{Results}

A total of 82 patients were available for this study, and after applying the inclusion and exclusion criteria, 46 were included (Figure 2). The median (interquartile range) of patient's age was 91 (87-93) years. All patients suffered from functional incontinence and chronic illness preventing them from going to the toilet or using a bedside commode. Additionally, their cognitive awareness was impaired, and they did not express the need to defecate and urinate; as a result, the RR of the variables for toileting ability was not calculated.

During the follow-up period, 25 patients $(54.3 \%)$ developed IAD. Most of IAD patients $(n=19$ [76\%]) only

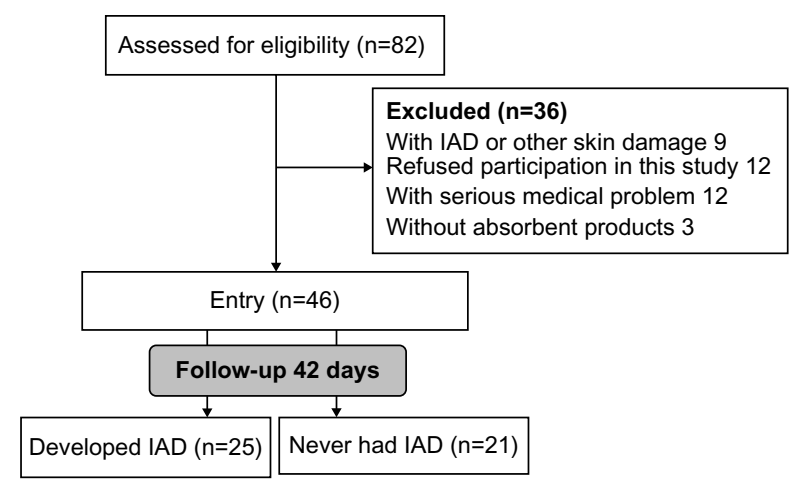

Figure 2 Flow chart displaying the process of study selection and the design. Abbreviation: IAD, incontinence-associated dermatitis. 
Table I Univariate analysis of the relative risk of developing incontinence-associated dermatitis

\begin{tabular}{|c|c|c|c|c|}
\hline & $\begin{array}{l}\text { Relative } \\
\text { risk }\end{array}$ & $95 \% \mathrm{Cl}$ & $P$ & $\begin{array}{l}\text { Attributable } \\
\text { risk }\end{array}$ \\
\hline \multicolumn{5}{|l|}{ Perineal environment } \\
\hline Frequency of absorbent pads changes ( $\geq 4$ times/day) & 2.439 & $0.4 I I-14.476$ & 0.357 & 28.8 \\
\hline Urine and feces incontinence & 2.037 & $0.763-5.438$ & 0.150 & 31.1 \\
\hline Contractures of the lower extremities & 0.682 & $0.328-1.421$ & 0.363 & -16.4 \\
\hline Bedridden state & 0.500 & $0.370-0.677$ & 0.114 & -50.0 \\
\hline Feces frequency ( $\geq 3$ times/week) & 2.528 & $1.317-4.852$ & 0.006 & 43.7 \\
\hline Loose or liquid stools & 9.677 & $1.43 \mid-65.445$ & $<0.001$ & 57.8 \\
\hline Malodorous urine & 5.489 & $1.907-15.799$ & $<0.001$ & 70.9 \\
\hline Turbid urine & 2.000 & $0.578-6.922$ & 0.260 & 25.0 \\
\hline Vaginal discharge & 0.638 & $0.326-1.247$ & 0.390 & -24.2 \\
\hline \multicolumn{5}{|l|}{ Tissue tolerance } \\
\hline Age $\geq 65$ years & 1.100 & $0.265-4.656$ & 1.000 & 4.5 \\
\hline Body mass index $<18.5 \mathrm{~kg} / \mathrm{m}^{2}$ & 1.013 & $0.560-1.83 \mid$ & 1.000 & 0.7 \\
\hline Skin maceration & 2.893 & $1.713-4.884$ & 0.001 & 59.5 \\
\hline Erythema index $\geq 46$ & 6.039 & $2.413-15.118$ & $<0.00$ I & 74.7 \\
\hline
\end{tabular}

Note: $\mathrm{n}=46$.

Abbreviation: $\mathrm{Cl}$, confidence interval.

developed pink redness, three (12\%) developed pink redness and rash, two (8\%) developed pink redness and skin loss, and one $(4 \%)$ developed pink redness, rash, and skin loss.

The cutoff EI for IAD development was identified by ROC curve analysis. An EI of 46 showed a sensitivity of 0.920 and specificity of 0.857 , whereas an EI of 48 showed a sensitivity of 0.840 and specificity of 0.952 . Therefore, EI $\geq 46$ was selected as potential risk factor of developing IAD, owing to the high sensitivity, and was used in the univariate analysis.

The selection of the potential risk factors was based on the univariate analysis of the RR of developing IAD (Table 1). Three factors from the perineal environment were identified: feces frequency (RR: 2.528, 95\% confidence interval [CI]: 1.317-4.852), loose or liquid stools (RR: $9.677,95 \% \mathrm{CI}$ : 1.431-65.445), and malodorous urine (RR: $5.489,95 \%$ CI: 1.907-15.799). Two variables from tissue tolerance were identified: skin maceration (RR: 2.893, 95\% CI: 1.713-4.884) and $\mathrm{EI} \geq 46$ (RR: 6.039, 95\% CI: 2.413-15.118).

Multivariable logistic regression analysis was conducted with the five potential risk factors. Among the perineal

Table 2 Multivariable logistic regression analysis for the risk factors of incontinence-associated dermatitis related to the perineal environment

\begin{tabular}{llll}
\hline & Odds ratio & $\mathbf{9 5 \%} \mathbf{C l}$ & $\boldsymbol{P}$ \\
\hline Feces frequency & 4.562 & $0.365-57.043$ & 0.239 \\
$\geq 3$ times/week & & & \\
Loose or liquid stool & 20.612 & $1.118-379.852$ & 0.042 \\
Malodorous urine & 37.094 & $3.480-395-399$ & 0.003 \\
\hline
\end{tabular}

Abbreviation: $\mathrm{Cl}$, confidence interval. environment factors, loose or liquid stools (odds ratio [OR]: 20.612, 95\% CI: $1.118-379.852, P=0.042)$ and malodorous urine (OR: $37.094,95 \% \mathrm{CI}: 3.480-395.399, P=0.003$ ) were significantly associated with the development of IAD (Table 2). Among the tissue tolerance factors, only EI $\geq 46$ (OR: 35.191, 95\% CI: 5.254-235.729, $P<0.001$ ) was significantly associated with the development of IAD (Table 3).

The discriminative validity of the three risk factors for the development of IAD was assessed by ROC curve analysis (Figure 3). Loose or liquid stools generated the highest specificity and positive predictive value, but the lowest sensitivity, negative predictive value, and positive likelihood ratio (Table 4). On the other hand, EI $\geq 46$ exhibited the highest sensitivity, negative predictive value, and positive likelihood ratio, with good specificity and positive predictive value (Table 4 ). These data suggest that the most valid predictor of IAD would be EI $\geq 46$.

\section{Discussion}

This study presents the complete analysis of the risk factors of IAD for elderly patients with incontinence, considering three main categories: perineal environment, tissue tolerance, and toileting ability. Previous studies mainly considered perineal environment and/or toileting ability. ${ }^{3,5,7-9}$ This more comprehensive

Table 3 Multivariable logistic regression analysis for the risk factors of incontinence-associated dermatitis related to tissue tolerance

\begin{tabular}{llll}
\hline & Odds ratio & $\mathbf{9 5 \%} \mathbf{C l}$ & $\boldsymbol{P}$ \\
\hline Skin maceration & II.20I & $0.817-153.535$ & 0.070 \\
Erythema index $\geq 46$ & $35.19 \mathrm{I}$ & $5.254-235.729$ & $<0.00 \mathrm{I}$ \\
\hline
\end{tabular}

Abbreviation: $\mathrm{Cl}$, confidence interval. 
Table 4 Receiver operating characteristic curve analysis of the significant risk factors of incontinence-associated dermatitis

\begin{tabular}{|c|c|c|c|c|c|c|c|}
\hline & AUC & $95 \% \mathrm{Cl}$ & Sensitivity & Specificity & PPV & NPV & $\overline{\text { PLR }}$ \\
\hline Loose or liquid stools & 0.747 & $0.577-0.916$ & 0.56 & 0.95 & 0.93 & 0.65 & 0.51 \\
\hline Malodorous urine & 0.851 & $0.709-0.992$ & 0.89 & 0.81 & 0.84 & 0.87 & 4.74 \\
\hline Erythema index $\geq 46$ & 0.847 & $0.703-0.991$ & 0.92 & 0.81 & 0.85 & 0.90 & 4.83 \\
\hline
\end{tabular}

Abbreviations: AUC, area under ROC curve; $\mathrm{Cl}$, confidence interval; PPV, positive predictive value; NPV, negative predictive value; PLR, positive likelihood ratio; ROC, receiver operating characteristic.

approach led to the identification of the most significant factors associated with IAD development, and these risk factors had the ability to predict the onset of IAD within a week of assessment of these risk factors. Most importantly, for the first time, this report identified $E I \geq 46$ as a risky skin condition for IAD and the most valid predictor of IAD development. Our previous study confirmed that median EI value of intact skin at the buttocks was 40.3 (interquartile range: 33.7-43.0). ${ }^{16}$

The three independent risk factors for IAD identified in this study are loose or liquid stools, malodorous urine, and EI $\geq 46$. The first two factors would cause the development of IAD, whereas EI is considered a trigger factor. Liquid stools are more alkaline and contain a higher concentration of metabolically active proteolytic and lipolytic enzymes, than normal stools. ${ }^{17}$ Therefore, they irritate the skin and cause IAD. Malodorous urine generally indicates anaerobic microflora, ${ }^{18}$ and foul odor may indicate presence of white blood cells. ${ }^{19}$ The bad odor is caused by bacterial ureases splitting urea into ammonia, which also raises the $\mathrm{pH}$ of urine..$^{19}$ Previous studies showed that malodorous urine is significantly associated with urinary tract infection (UTI ${ }^{20-22}$ and the presence of nitrite and leukocyte esterase. ${ }^{20}$ In fact, the levels of nitrite and leukocyte esterase in malodorous urine were identified as good indicators of UTI. ${ }^{23}$ Therefore, the alkaline $\mathrm{pH}$ of malodorous urine may irritate the skin and cause IAD. However, our study was not designed to identify

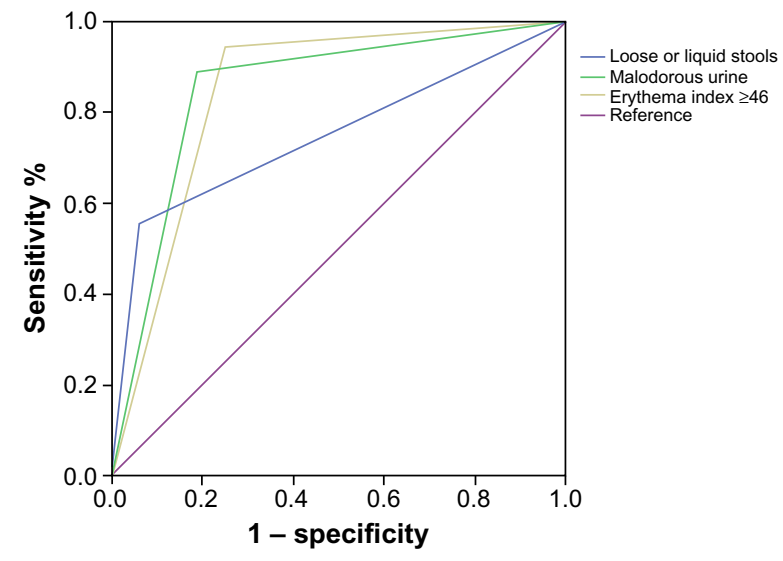

Figure 3 Receiver operating characteristic curves for the risk factors of incontinence-associated dermatitis in elderly patients. the cause of the malodorous urine. Therefore, further research is required to reveal the association between malodorous urine and infected urine.

Among the skin characteristics, EI was identified as a valid predictor of IAD, but not skin maceration. By definition, skin maceration is caused by prolonged exposure to moisture, which could be water or urine. Accordingly, we thought that skin maceration would constitute a specific predictor of IAD. Skin maceration caused by only water without irritant might not be a risk condition for IAD because of the absence of inflammation. EI provides a quantitative measurement of skin inflammation ${ }^{24,25}$ and was consequently identified, in the present study, as the most valid risk indicator of IAD.

\section{Implementation}

The three risk factors of IAD identified in this study are useful and easy to use in clinical practice because they are evaluated without special skills or expensive instruments. Therefore, we propose a new risk assessment tool for IAD, based on these factors (Figure 4). The workflow would start with the measurement of EI at the time of admission. If EI $\geq 46$, preventive care, ie, current best practice recommendations, ${ }^{26}$ should be provided to the patient. If EI $<46$, the patient should be monitored for loose or liquid stools and malodorous urine. If one of these two factors is confirmed, preventive care should be provided to the patient.

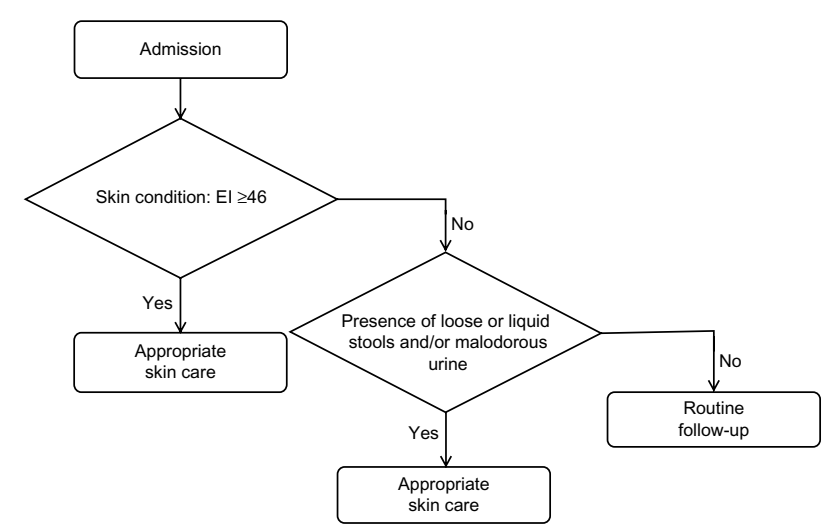

Figure 4 Decision tree of the new risk assessment tool for incontinence-associated dermatitis in elderly patients.

Abbreviation: El, erythema index. 
Preventive care for IAD is not always provided to the patient when needed because the medical staff has insufficient patient information on the incontinence immediately after admission. On the other hand, the present study shows that the patients can be monitored regularly for EI to prevent the development of IAD. The assessment method is rapid and noninvasive, and the 3 minutes required to take a photograph can easily be inserted in the daily routine of the caretakers.

\section{Limitations}

This study presents some limitations. The strength of the association between the risk factors of IAD and the development of IAD could not be determined due to the small sample size. The risk assessment tool proposed herein is limited to the buttocks because the cutoff EI may be different in other regions with different skin properties, such as the groin and pudendum. Likewise, the use of this risk assessment tool for young individuals would require validation, due to changing skin conditions with age.

\section{Conclusion}

This is the first study reporting EI as index of a skin condition at risk for the development of IAD. In addition, loose or liquid stools and malodorous urine were significantly associated with IAD development. These three risk factors of IAD allowed us to design a new highly valid risk assessment tool that is easily implemented in clinical practice.

\section{Acknowledgments}

We wish to express our sincerest gratitude to Ms Keiko Tabata and Dr Toru Sugiyama for their permission and cooperation during the investigation. We are also thankful for the generous support from the participants and staff members of the Sengi Hospital, Ishikawa Prefecture, Japan. We are deeply grateful to Dr Shigeru Kawara for conducting the identification of IAD and skin maceration.

\section{Disclosure}

The authors report no conflicts of interest in this work.

\section{References}

1. Gray M, Bliss DZ, Doughty DB, Ermer-Seltun J, Kennedy-Evans KL, Palmer MH. Incontinence-associated dermatitis: a consensus. $J$ Wound Ostomy Continence Nurs. 2007;34(1):45-54; quiz 55-56.

2. Bliss DZ, Savik K, Harms S, Fan Q, Wyman JF. Prevalence and correlates of perineal dermatitis in nursing home residents. Nurs Res. 2006;55(4): 243-251.

3. Shigeta Y, Nakagami G, Sanada H, et al. Exploring the relationship between skin property and absorbent pad environment. J Clin Nurs. 2009;18(11):1607-1616.

4. Bale S, Tebble N, Jones V, Price P. The benefits of implementing a new skin care protocol in nursing homes. JTissue Viability. 2004;14(2): $44-50$.
5. Zimmaro Bliss D, Zehrer C, Savik K, Thayer D, Smith G. Incontinence-associated skin damage in nursing home residents: a secondary analysis of a prospective, multicenter study. Ostomy Wound Manage. 2006;52(12):46-55.

6. Long MA, Reed LA, Dunning K, Ying J. Incontinence-associated dermatitis in a long-term acute care facility. $J$ Wound Ostomy Continence Nurs. 2012;39(3):318-327.

7. Bliss DZ, Savik K, Thorson MA, Ehman SJ, Lebak K, Beilman G. Incontinence-associated dermatitis in critically ill adults: time to development, severity, and risk factors. $J$ Wound Ostomy Continence Nurs. 2011;38(4):433-445.

8. Kottner J, Blume-Peytavi U, Lohrmann C, Halfens R. Associations between individual characteristics and incontinence-associated dermatitis: A secondary data analysis of a multi-centre prevalence study. Int J Nurs Stud. Epub February 23, 2014.

9. Nix DH. Validity and reliability of the Perineal Assessment Tool. Ostomy Wound Manage. 2002;48(2):43-46, 48.

10. Brown DS. Perineal dermatitis risk factors: clinical validation of a conceptual framework. Ostomy Wound Manage. 1995;41(10):46-48, $50,52-53$.

11. Ichikawa-Shigeta Y, Sugama J, Sanada H, et al. Physiological and appearance characteristics of skin maceration in elderly women with incontinence. J Wound Care. 2014;23(1):18-19, 22.

12. Borchert K, Bliss DZ, Savik K, Radosevich DM. The incontinenceassociated dermatitis and its severity instrument: development and validation. $J$ Wound Ostomy Continence Nurs. 2010;37(5):527-535.

13. Fleiss JL, Levin B, Paik MC. Statistical Methods for Rates and Proportions. 3rd ed. New York, NY: John Wiley and Sons; 2004.

14. Yamamoto T, Takiwaki H, Arase S, Ohshima H. Derivation and clinical application of special imaging by means of digital cameras and Image J freeware for quantification of erythema and pigmentation. Skin Res Technol. 2008;14(1):26-34.

15. O'Donnell LJ, Virjee J, Heaton KW. Detection of pseudodiarrhoea by simple clinical assessment of intestinal transit rate. $B M J$. 1990;300(6722):439-440.

16. Ichikawa Y, Sanada H, Konya C, et al. Assessment of skin maceration as a risk indicator of incontinence-associated dermatitis. Presented at the 20th IAGG World Congress of Gerontology and Geriatrics; June 23-27, 2013; Seoul, Korea.

17. Gray M, Black JM, Baharestani MM, et al. Moisture-associated skin damage: overview and pathophysiology. $J$ Wound Ostomy Continence Nurs. 2011;38(3):233-241.

18. Meislin HW. Pathogen identification of abscesses and cellulitis. Ann Emerg Med. 1986;15(3):329-332.

19. Brunzel NA. Fundamental of Urine and Body Fluids Analysis. 3rd ed. St Louis, MO: Elsevier Saunders; 2013.

20. Gauthier M, Gouin S, Phan V, Gravel J. Association of malodorous urine with urinary tract infection in children aged 1 to 36 months. Pediatrics. 2012;129(5):885-890.

21. Couture E, Labbé V, Cyr C. Clinical predictors of positive urine cultures in young children at risk for urinary tract infection. Paediatr Child Health. 2003;8(3):145-149.

22. Juthani-Mehta M, Quagliarello V, Perrelli E, Towle V, Van Ness PH, Tinetti M. Clinical features to identify urinary tract infection in nursing home residents: a cohort study. JAm Geriatr Soc. 2009;57(6):963-970.

23. Williams GJ, Macaskill P, Chan SF, Turner RM, Hodson E, Craig JC. Absolute and relative accuracy of rapid urine tests for urinary tract infection in children: a meta-analysis. Lancet Infect Dis. 2010;10(4):240-250.

24. Gawkrodger DJ, McDonagh AJ, Wright AL. Quantification of allergic and irritant patch test reactions using laser-Doppler flowmetry and erythema index. Contact Dermatitis. 1991;24(3):172-177.

25. Ohshima H, Takiwaki H, Washizaki K, Ishiko A, Itoh M, Kanto H. Quantitative evaluation of patch test reactions: a comparison between visual grading and erythema index image analysis. Skin Res Technol. 2011;17(2):220-225.

26. Callan C, Beals D, Harwood JK, et al. Incontinence Associated Dermatitis (IAD): Best Practice for Clinicians. Mt Laurel, NJ: Wound Ostomy and Continence Nurses (WOCN) Society; 2011. 


\section{Publish your work in this journal}

Chronic Wound Care Management and Research is an international, peer reviewed, open access, online journal publishing original research, reviews, editorials, and commentaries on the causes and management of chronic wounds and the major issues related to chronic wound management. Topics also include chronic wounds as comorbidities to other conditions, patient adherence to therapy, and the economic burden of chronic wounds. The manuscript management system is completely online and includes a very quick and fair peer review system, which is all easy to use. Visit http://www.dovepress.com/testimonials.php to read real quotes from published authors.

Submit your manuscript here: http://www.dovepress.com/chronic-wound-care-management-and-research-journal 